\title{
Perfil oxidativo e leucometria de ovelhas de corte acometidas por mastite crônica*
}

\section{White cell count and oxidative profile in sheep affected by chronic mastitis}

\author{
José Francisco Xavier da Rocha, ${ }^{* *}$ Felipe Lamberti Pivoto, ${ }^{* * *}$ Adelina Rodrigues Aires, ${ }^{* * *}$ Ricardo Xavier da Rocha, ${ }^{* * * *}$ \\ José Francisco Manta Bragança, ${ }^{* * *}$ Rafael Moresco, ${ }^{* * *}$ Vanessa Torbitz, ${ }^{* * *}$, Agueda Vargas, ${ }^{* * *}$ Claudia Balzan, ${ }^{* * * * *}$ \\ Marta Lizandra do Rêgo Leal ${ }^{* \star *}$
}

\begin{abstract}
Resumo
O objetivo deste estudo foi avaliar o perfil oxidativo e o leucometria de ovelhas de corte com mastite crônica. Para isso foram utilizados 30 animais em lactação, os quais foram divididos em dois grupos de 15 animais: grupo positivo - animais que exibiram sinais clínicos de mastite e grupo negativo - ovelhas sem sinais de alteração na glândula mamária e/ou no leite. Para realização do California Mastitis Test (CMT) e exame microbiológico foram coletadas amostras de leite e para determinar o total de leucócitos, o índice de estresse oxidativo (OSI) e o óxido nítrico foram coletadas amostras de sangue. Sessenta por cento das ovelhas com mastite apresentaram CMT positivo. Não houve diferença entre os grupos nos valores de leucócitos, de OSI e no óxido nítrico. Em decorrência da redução do processo inflamatório, ovelhas com mastite crônica não apresentam alterações no perfil oxidativo e no total de leucócitos.
\end{abstract}

Palavras-chave: ovinos, perfil oxidativo, mastite, leucócitos.

\begin{abstract}
In this study 30 lactating sheep were used to evaluate the oxidative profile and leucocytes of animals with chronic mastitis. Groups, containing 15 animals each, were divided into: group of positive animals presenting clinical signs of mastitis, and control group containing animals which did not present alterations in the mammal gland or in the milk. Milk samples were collected and the California Mastitis Test (CMT) and microbiologic examination were performed. In addition, the total of leukocytes, total antioxidant capacity (TAC), total oxidant status (TOS) and nitric oxide were measured through blood analyses. Sixty percent of the animals with mastitis presented CMT positive. There was no difference in the values of leukocytes, OSI and nitric oxide between groups. Sheep with chronic mastitis did not present alterations in the oxidative profile and total leukocytes, due to the reduction of the inflammation.
\end{abstract}

Keywords: sheep, oxidative profile, mastitis, leukocytes.

\section{Introdução}

A mastite é um processo inflamatório da glândula mamária, causada por traumatismos ou infecção por micro-organismos. Dependendo da presença ou não de sinais, pode ser denominada de mastite clínica ou de mastite subclínica. A apresentação clínica está relacionada com o aparecimento de sinais na glândula mamária como aumento da temperatura, edema e rubor, além de dor à palpação. Já a sua forma crônica manifesta-se mediante palpação de nódulos e fibrose no parênquima glandular (Fitzpatrick et al., 2006).

Esta enfermidade causa alterações quantitativas e qualitativas no leite, além de sérios prejuízos econômicos devido ao descarte precoce das ovelhas e redução na produção de leite com consequente aumento na taxa de mortalidade de cordeiros (Peixoto et al., 2010).

Na mastite subclínica não há evidência de sinais clínicos na glândula mamária, e para seu diagnóstico é utilizado rotineiramente o California Mastitis Test (CMT). Os principais agentes causadores de mastite clínica em ovinos são os Staphylococcus spp., mas também podem ser isolados Streptococcus, Mannheimia haemolytica e algumas espécies de fungos (Peixoto et al., 2010).

O sistema mamário possui uma série de respostas imunológicas ao processo infeccioso levando a uma resposta quimiotáxica de neutrófilos e macrófagos (Aitken et al., 2011). Neste contexto, o sistema antioxidante (SA) possui um papel importante, principalmente na sanidade animal (Lykkesfeldt e Svendsen, 2007).

O SA tem papel fundamental na defesa contra a produção excessiva de espécies reativas de oxigênio (EROS) e de nitrogênio (ERN) geradas durante processo inflamatório (Halliwell e Gutteridge, 2007). Uma vez formadas as espécies reativas atuam doando ou recebendo um elétron de moléculas vizinhas. Quando a quantidade de espécies reativas produzidas excede a capacidade antioxidante orgânica, forma-se uma reação em

${ }^{*}$ Recebido em 20 de setembro de 2014 e aceito em 7 de março de 2016

**Departamento de Medicina Veterinária, Universidade do Oeste de Santa Catarina, São Miguel do Oeste, Brasil.

${ }^{* * *}$ Departamento de Medicina Veterinária, Universidade Federal de Santa Maria, Santa Maria, Brasil.

****Departamento de Medicina Veterinária, Universidade do Oeste de Santa Catarina, Xanxerê, Brasil.

*****Departamento de Bacteriologia, Universidade Federal de Santa Maria, Santa Maria, Brasil.

Autor para correspondência: martalizandra@gmail.com 
cadeia causando danos ao organismo, o que denominamos de estresse oxidativo, o qual está intimamente relacionado a patogênese de doenças pois prejudica diretamente a resposta fisiológica contra enfermidades (Lykkesfeldt e Svendsen, 2007). Em um processo inflamatório como na mastite, ocorre a liberação de uma série de moléculas, entre eles as espécies reativas de oxigênio e de nitrogênio (Sordillo, 2005), sendo que o principal radical livre envolvido neste processo é o oxido nítrico (Notebaert et al., 2008).

Estudos acerca de perfil oxidativo em ovelhas de carne com mastite crônica não foram relatados até o momento, com isso, o objetivo deste estudo foi avaliar o perfil oxidativo e leucometria de ovelhas de corte com mastite crônica.

\section{Material e métodos}

O estudo foi realizado em São Martinho da Serra - RS, com 30 ovinos da raça Texel em lactação, sendo $15 \mathrm{com}$ sinais de mastite clínica (Grupo positivo) e 15 sem alterações na glândula mamária e/ou no leite (Grupo negativo). A coleta de amostras de leite foi realizada com prévia higienização dos tetos, onde os três primeiros jatos foram desprezados e realizado o CMT com $2 \mathrm{~mL}$ de leite. As amostras de leite consideradas positivas no CMT foram alocadas em frascos estéreis, identificadas e encaminhadas para o laboratório de bacteriologia da Universidade Federal de Santa Maria (LABAC), e então realizado a cultura microbiológica, para isolamento do agente, e o teste de susceptibilidade aos antimicrobianos (Mac Faddin, 2000).

Amostras de sangue foram coletadas por venopunção da jugular com uso de vacuntainer ${ }^{\circledR}$ em um tubo de $10 \mathrm{~mL}$ sem anticoagulante e outro tubo de $5 \mathrm{~mL}$ com anticoagulante. As amostras de sangue sem anticoagulante foram centrifugadas e o soro utilizado para determinação da Capacidade Antioxidante Total (TAC) conforme descrito por Erel (2004) e do Status de Oxidação Total (TOS) conforme descrito por Erel (2005), para determinação do índice de estresse oxidativo (OSI) através da formula [(TOS, $\mu \mathrm{mol} / \mathrm{L})$ / (TAC, $\mu \mathrm{mol}$ Trolox equivalent/L) $x$ 100] (Aycicek et al., 2005). Ainda com a utilização do soro foi determinada a concentração de oxído nítrico mediante técnica descrita por Tatsch et al. (2011). O total de leucócitos foi determinado em câmara de Neubauer modificada (Thrall, 2007).

Os dados foram submetidos ao teste de normalidade Kolmogorov-Sminov e os que apresentaram distribuição normal (OSI e contagem de leucócito) foram submetidos ao teste T e os que não apresentaram distribuição normal (NO) ao teste Mann-Whitney, ambos com intervalo de confiança de 95\%. Os resultados foram expressos em médias \pm erro padrão. O presente trabalho foi aprovado pelo comitê de ética da Universidade Federal de Santa Maria sob o número do parecer 013/2014.

\section{Resultados e discussão}

Ao exame clínico geral nenhum animal apresentou alteração nas funções vitais, porém, na avaliação da glândula mamária, os 15 animais do grupo positivo apresentaram nódulos, edema de úbere e fibrose. No CMT $60 \%$ das ovelhas do grupo positivo tiveram seus resultados considerados fortemente positivos (+++) conforme classificação descrita por Schalm e Noorlander (1957). De acordo com Hartman et al. (2009) existe uma alta correlação entre a positividade no CMT e a quantidade de células somática no leite, considerando este teste confiável apesar de subjetivo, com amostras de leite classificadas com três ou mais cruzes, contendo em torno de 1200,00 células $/ \mathrm{mL}$.

O principal agente isolado nas amostras de leite dos animais do grupo positivo foi o Staphylococcus spp., agente esse considerado o principal causador de mastite em ovinos. Relatos avaliando o agente causador de mastite em ovelhas de corte ainda são escassos, os quais sugerem que exista uma grande diversidade de agentes patogênicos em ovinos com esta aptidão (Peixoto et al., 2010).

O grupo positivo apresentou $6.150 \pm 2086,67$ leucócitos enquanto que no grupo negativo foi de $6.996 \pm 1990,01$, não demonstrando diferença entre os grupos, possivelmente pela cronicidade da enfermidade e os agentes envolvidos neste estudo. Em estudo com pequenos ruminantes, Pinheiro Junior et al. (2006) avaliaram alterações no leucograma de animais afetados por mastite causada por Corynebacterium pseudotuberculosis, além de relacionar este quadro clínico a apresentações agudas da enfermidade. Nestas situações, ocorre uma grande liberação de substâncias adrenocorticais comum no início de doenças infecciosas ou inflamatórias. Esta alteração transitória pode refletir no total de leucócitos de animais infectados, porém quando há cronicidade da doença os valores tendem a estar dentro do fisiológico para espécie (Thrall, 2007), o que pode explicar não ter sido observado diferença entre os grupos.

Os valores de óxido nítrico foram de $150,8 \pm 39,5$ e $279,8 \pm$ 71,2 no grupo positivo e negativo, respectivamente. Estes dados apresentam uma característica peculiar principalmente relacionando a cronicidade da enfermidade nestes animais. Em quadros agudos é normal termos um aumento do óxido nítrico, principalmente pela sua atuação nas funções do organismo relacionadas a processos inflamatórios (Dawson e Dawson, 1995). Sua produção aumenta consideravelmente quando temos um maior fluxo de células epiteliais e macrófagos em processos como os que envolvem a mastite (Bouchard et al., 1999). Este aumento nos quadros agudos pode ser explicado pela formação do radical peroxinitrito, oriundo da condensação entre o radical superóxido e o óxido nítrico (Wang et al., 2002).

O OSI do grupo controle foi de 7,19 \pm 0,97 e do grupo negativo de $6,23 \pm 0,69$, dados esses desconhecidos quando se trata de mastites em ovelhas com aptidão para produção de carne. Em enfermidades relacionadas a glândula mamária, principalmente as que causam inflamação este índices apresentam grande variação. Em estudo no leite de bovinos com mastite subclínica, Atakisi et al. (2010) observaram que existe uma inversão entre estes parâmetros no leite, aumentando os valores de oxidantes totais reduzindo a resposta antioxidante, resultando em uma divergência no metabolismo oxidativo. A particularidade do presente estudo, é que ele mostra que assim como outros parâmetros, a mastite quando apresentada na sua forma crônica tende a regular o balanço entre substâncias oxidantes e antioxidantes, estabilizando o status oxidativo. Conclui-se que o perfil oxidativo e o numero total de leucócitos não é alterado quando ocorre a cronicidade em mastite de ovelhas com aptidão para carne. 


\section{Referências}

ATAKISI, O.; ORAL, H.; ATAKISI, E.; MERHAN, O.; PANCARCI, S.M.; OZCAN, A.; MARASLI, S.; POLAT, B.; COLAK, A.; KAYA, $S$. Subclinical mastitis causes alterations in nitric oxide, total oxidant and antioxidant capacity in cow Milk. Research in Veterinary Science, v.89, n.1, p.10-13, 2010.

AITKEN, S.L.; CORL, C.M.; SORDILLO, L.M. Immunopathology of mastitis: insights into disease recognition and resolution. Journal of Mammary Gland Biology and Neoplasia, v.16, n.4, p.291-304, 2011.

AYCICEK, A.; EREL, O.; KOCYIGIT, A. Decreased total antioxidant capacity and increased oxidative stress in passive smoker infants and their mothers. Pediatrics International, v.47, n.6, p.635-639, 2005.

BOUCHARD, L.; BLAIS, S.; DESROSIERS, C.; ZHAO, $X$.; LACASSE, P. Nitric oxide production during endotoxininduced mastitis in the cow. Journal of Dairy Science, v.82, n.12, p.2574-2581, 1999.

DAWSON, T.M.; DAWSON, V.L. Nitric Oxide: Actions and pathological roles. The Neuroscientist, v.1, n.1, p.7-18, 1995.

EREL, O. A novel automated method to measure total antioxidant response against potent free radical reactions. Clinical Biochemistry, v.37, n.2, p.112-119, 2004.

EREL, O. A new automated colorimetric method for measuring total oxidant status. Clinical Biochemistry, v.38, n.12, p.1103-11, 2005.

FITZPATRICK, J., SCOTT, M.; NOLAN, A. Assessment of pain and welfare in sheep. Small Ruminant Research, v.62, n.1, p.55$61,2006$.

HALLIWELL, B.; GUTTERIDGE J. Free radicals in biology and medicine. 4 ed. United Kingdow: Oxford University Press, 2007, $704 \mathrm{p}$.

HARTMAN, M.; BOLSANELLO, R.X.; DOMINGUES, P.F.; MELLO JÚNIOR, A.S.; LANGONI, H. Efeito da mastite sobre a contagem de células somáticas (CCS) em ovelhas da raça Bergamácia.

Veterinária e Zootecnia, v.16, n.1, p.213-220, 2009.
LYKKESFELDT, J.; SVENDSEN, O. Oxidants and antioxidants in disease: Oxidative stress in farm animals. The Veterinary Journal, v.173, n.3, p.502-511, 2007

MAC FADDIN, J.F. Biochemical tests for identification of medical bacteria. 3 ed. United States of America: Lippincott Williams \& Wilkins, 2000, $912 \mathrm{p}$.

NOTEBAERT, S.; DEMON, T.; BERGHE, T.V.; VANDENABEELE, P.; MEYER, E. Inflammatory mediators in Escherichia coli induced mastitis in mice. Comparative immunology, microbiology and infectious diseases, v.31, n.6, p.551-565, 2008

PEIXOTO, R.D.M., MOTA, R.A.; COSTA, M.M. Mastite em pequenos ruminantes no Brasil. Pesquisa Veterinária Brasileira, v.30, n.9, p.754-762, 2010.

PINHEIRO JUNIOR, J.W.; OLIVEIRA, A.A.F.; ALVES, F.S.F.; SILVA, L.B.G.; RABELO, S.S.A.; MOTA, R.A. Corynebacterium Pseudotuberculosis experimental infection of goats mamary gland. Arquivos do Instituto Biológico, v.73, n.4, p.395-400, 2006.

SCHALM, O.W.; NOORLANDER D.O. Experiments and observations leading to development of the California mastitis test. Journal of the American Veterinary Medical Association, v.130, n.5, p.199-204, 1957.

SORDILLO, L.M. Factors affecting mammary gland immunity and mastitis susceptibility. Livestock Production Science, v.98, n.1, p.89-99, 2005

TATSCH, E.; BOCHI, G.V.; PEREIRA, R.S.; KOBER, H.; AGERTT, V.A.; CAMPOS, M.M.A.; GOMES, P.; DUARTE, M.M.F.; MORESCO, R.N. A simple and inexpensive automated technique for measurement of serum nitrite/nitrate. Clinical Biochemistry, v.44, n.4, p.348-350, 2011.

THRALL, M.A. Hematologia e bioquímica clínica veterinária. 1 ed. Brasil: Editora Roca, 2007, 592 p.

WANG, P.G.; XIAN, M.; TANG, X.; WU, X.; WEN, Z.; CAI, T.; JANCZUK, A.J. Nitric oxide donors: chemical activities and biological applications. Chemical Reviews, v.102, n.4, p.10911134, 2002. 